\title{
INHERITANCE OF RESISTANCE TO PSTV IN TRANSGENIC PEANUTS CONTAINING cp PStV GENE
}

\author{
Dwi Hapsoro ${ }^{1}$, Hajrial Aswidinnoor ${ }^{2}$, Rusmilah Suseno ${ }^{3}$ Jumanto $^{4}$, dan Sudarsono ${ }^{2}$
}

\begin{abstract}
Inheritance of Resistance to PStV in Transgenic Peanuts Containing cp PStV Gene. We have obtained transgenic peanut lines containing coat protein gene of PStV. To get maximal use of the transgenic character in a breeding program, it is necessary that the transgene is also stably inherited and expressed. This experiment was conducted from June $2002-$ January 2005 at Plant Molecular Biology Laboratory, Bogor Agricultural University, and Queensland Agricultural Biotechnology Center, The University of Queensland, Australia. The research aimed (1) to test whether PStV $c p$ transgene was functional in progenies derived from crosses between transgenic peaanut plants containing PStV $c p$ gene and nontransgenic ones and (2) to determine pattern of inheritance of resistance to PStV as a result of PStV $c p$ gene action. Several crosses were made between trangenic peanut cv.Gajah resistant to PStV (T4 generation) and non-transgenic peanut line WS susceptible to PStV. The F1 and F2 populations were mechanically inoculated with PStV two weeks after planting. The experiment showed that all plants in the F1 population were less susceptible to PStV, suggesting that the transgene was partially dominant. Phenotipic segregation in F2 population was not Mendelian with the appearance of quick and slow recovery plants and the number of resistant plants being more than expected. However, the proportion of transgenic and non-transgenic plants followed 3:1 ratio, which was Mendelian.
\end{abstract}

Key words : transgenic peanuts, PStV, $c p$ gene, resistance, inheritance.

\section{INTRODUCTION}

We have reported transgenic peanut plants containing Peanut Stripe Virus (PStV) coat protein gene and their response to PStV infection, i.e. resistance, recovery, and susceptible response to PStV infection (Hapsoro et al., 2005; 2007a; 2007b). Resistant plants were those that showed no symptoms of disease caused by PStV. Recovery plants were those that showed chlorotic ring mottle on one or more leaves and no symptoms on newly emerging leaves. Susceptible plants were those that showed severe blotch symptom on one leaf and all newly emerging leaves. Less susceptible plants were the same as susceptible ones except that the symptom was chlorotic ring mottle.

Southern analysis of the transgenic peanuts showed that transgene $1.1 \mathrm{~kb}$ and $1.3 \mathrm{~kb}$ resulted in resistant or recovery response to PStV (Hapsoro et al., 2007a). In some transformants, the transgene was stabile, as indicated by the transgenic plants being resistant for seven generations of selfing. We have also obtained some pure lines of transgenic peanut plants. For the transgenic peanuts to be used as parents in a breeding program, it was necessary to determine whether the transgene was functional in progenies resulted from crosses between the transgenic peanuts and non-transgenic ones. In addition, the transgene inheritance needed to be elucidated so that it could be used as a basis for designing a breeding program.

Transgenic plants resulted from different independent transformation events showed different pattern of inheritance even though the gene construct was the same. (Peach and Velten 1991, Spencer et al., 1992, Walters et al., 1992). This was thought to be influenced by integration sites, number of integration sites, cofiguration of transgenic loci, and whether or not there was epigenetic silencing . (Peach and Velten 1991, Spencer et al., 1992, Walters et al., 1992).

This research aimed (1) to test whether PStV $c p$ transgene was functional in progenies derived from crosses between transgenic peanut plants containing PStV cp gene and non-transgenic ones and (2) to determine pattern of inheritance of resistance to PStV.

\section{MATERIALS AND METHODS}

Plant materials. This experiment used transgenic peanuts cv.Gajah containing PStV cp gene that has been previously reported (Hapsoro et al., 2006). Transgenic parents used in this experiment were T4

\footnotetext{
${ }^{1}$ Department of Agronpmy, faculty of Agriculture, Lampung University

${ }^{2}$ Plant Molecular Biology Lab, Department of Agronomy and Horticulture, Faculty of Agriculture, Bogor Agricultural University

${ }^{4}$ Department of Plant Protection, Faculty of Agriculture, Bogor Agricultural University, Jl Meranti, Kampus IPB Darmaga, Bogor 16680.

${ }^{3}$ BB Biogen, Bogor, Jl Tentara Pelajar, Bogor
} 
plants derived from one T0 plants resulted from one transformation event. One regenerant derived from one transformation event was clonally propagated in vitro through axillary branching. T0 plants were grown to maturity in plastichouse. $\mathrm{T}_{0: 1}$ seeds were sown to get $\mathrm{T} 1$ plants that were grown to produce $\mathrm{T}_{1: 2}$ seeds. $T_{1: 2}$ seeds were sown to get $\mathrm{T} 2$ plants that were grown to produce $T_{2: 3}$ seeds. Such selfings were conducted until four generations and in so doing T4 plants were obtained.

Nomenclature of plants employed in this experiment is as follows. T0 plants were designated as G. $T_{1}, T_{2}, T_{3}$, and $T_{4}$ plants were designated as $G(n)$, G(n.o), G(n.o.p), G(n.o.p.q), and G(n.o.p.q), respectively, where $\mathrm{n}, \mathrm{o}, \mathrm{p}$, and $\mathrm{q}$, are cardinal numbers,. As an ilustration, G (1) is a T1 plant number $1, G(2)$ is a T1 plant number 2, G (3) is a T1 plant number 3 , and so on. $\mathrm{G}$ ( 1.1$)$ is a T2 plant number 1 derived from $G$ (1). G (1.2) is a T2 plant number 2 derived from $G$ (1). G (2.1) is a T2 plant number 1 derived from G (2). Arbitrarily, G (8.10.8.4) is a T4 plant number 4 derived from a T3 plant $\mathrm{G}$ (8.10.8).

Transgenic parents used for crossing in this experiment were $G$ (8.10.8.1), G (8.10.8.2), G (8.10.8.4), G (8.10.8.5), G (9.2.5.2), dan G (9.2.5.5), while non-transgenic parent used was line WS. Nomenclature used for F1 plants was as follows. WS/ G (9.2.5.2).1, for example, was a number 1 member of F1 population resulted from a cross between line WS as a female parent and a transgenic plant $G$ (9.2.5.2) as a male parent. WS/ G (9.2.5.2).2 was a number 2 member of $\mathrm{F} 1$ of the same cross, and so on. Arbitrarily, WS/G (8.10.8.1).6 was a number 6 member of $\mathrm{F} 1$ population from a cross between line WS as a female parent and G (8.10.8.1) as a male parent.

All plants were grown in an insect-proof plastichouse. Plants were grown in polybags $(45 \mathrm{~cm} \mathrm{x}$ $50 \mathrm{~cm}$ ) containing a mixture of soil and sand (2:1). Watering was done to field capacity. Pest control was carried out using imidakloprit and dikofol, while disease control was conducted using mankozeb.

PStV inoculation. F1 plants were mechanically inoculated with PStV at least three times, i.e. at 2, 4 and 6 weeks after planting. Further inoculation every two weeks were done on plants that did not show disease symptom to ensure that the plants were really resistant. PStV inoculation was also conducted on non-transgenic peanuts cv.Gajah and line WS as a control.

Inoculum of PStV was maintained and propagated in peanut plants cv. Kelinci which had been inoculated with PStV isolate Bogor that caused severe blotch-stripe symptom in peanut plants cv. Landak (Akin, 1999; Avivi, 2000; Yasin, 2001). The fully opened youngest leaves were spread with carborundum powder (600 mess) and rubbed with cutton bud previously dipped in inoculum solution. The inoculum was prepared by grinding PStVinfected leaves $(0.5 \mathrm{~cm}$ in diameter) in $200 \mu \mathrm{l}$ of phosphate buffer solution $\mathrm{pH}$ 7. Effectiveness of the inoculation was evaluated using an indicator plant, i.e Chenopodium amaranticolor.

Southern analysis. The transgenic parents used were G(8.10.8.1), G(8.10.8.2), G(8.10.8.4), G(8.10.8.5), $G(9.2 .5 .2)$, and $G(9.2 .5 .5)$, that were progenies of the resistant line $G$ (8.10.8) and $G(9.2 .5)$. Some of the progenies of those two resistant lines i.e. G(8.10.8.4.1), G(8.10.8.6.3), $\quad G(9.2 .5 .1 .1), \quad$ and G(9.2.5.1.2) were subjected to Southern analysis.

Total nucleic acid was extracted using CTAB method (Murray and Thompson, 1980). Four or five leaves were frozen in liquid nitrogen and ground to powder using pestle and mortar. The powdered leaves were added with 3-4 $\mathrm{ml}$ of extraction buffer of $65^{\circ} \mathrm{C}$, shaken slowly, and the suspension was incubated for 1 hour in a water bath at $65^{\circ} \mathrm{C}$. The suspension was added with the same volume of chloroform and isoamylalcohol mix (24:1), slowly shaken, and centrifuged at 10,000 rpm at room temperature for 30 minutes. The liquid phase on the upper part was pipetted and put into a new tube, added with 0.6 volume of isopropanol and 0.1 volume of sodium acetate $5 \mathrm{M}$, incubated for 10 minutes, and centrifuged at $10,000 \mathrm{rpm}$ at room temperature for 30 minutes. The supernatant was removed and the pellet was resuspended with alcohol $70 \%$, centrifuged at 8,000 $\mathrm{rpm}$ at room temperature for 20 minutes. The pellet was solubilized in $500 \mu \mathrm{l}$ of aquadest and DNA concentration in the solution was measured using spectrophotometer at $260 \mathrm{~nm}$. DNA samples $(2-5 \mu \mathrm{l})$ were run in gel electrophoresis with agarose $1 \%$ to confirm the quality of the DNA.

Southern analysis was conducted according to Higgins and Dietzgen (2000). DNA (10-20 $\mu \mathrm{g})$ in 
150-300 $\mu \mathrm{l}$ of aquadest was digested overnight with NcoI at $37^{\circ} \mathrm{C}$. The solution was added with 2.5 volume of ethanol $100 \%$ and 0.1 volume of sodium acetate $5 \mathrm{M}$ and incubated at $-20^{\circ} \mathrm{C}$ for 2 hours. The mixture was centrifuged at $13,000 \mathrm{rpm}$ and at $4^{\circ} \mathrm{C}$ for 30 minutes. The DNA pellet was washed by adding with ethanol and spinning at $13,000 \mathrm{rpm}$ for 10 minutes. The DNA was solubilized in $50 \mu \mathrm{l}$ sterile aquadest.

The DNA solution was electrophoresed in agarose $1 \%$ at 80 volt for 3 hours. The agarose gel was shaken in denaturing solution for 2 x 20 minutes and in neutralization solution for $2 \times 20$ minutes. The DNA was transferred to positively charged nylon membrane using capillary method overnight. Hybridization reaction was done using a radioactively $\left({ }^{32} \mathrm{P}\right)$ labeled DNA as a probe to detect the transgene and the result was visualized.

\section{RESULTS AND DISCUSSION}

As previously reported (Hapsoro et al., 2007a), there were five types of resposes to PStV infection: resistant, quick recovery, slow recovery, less susceptible, and susceptible. Resistant plants (score 0) were those that showed no symptoms of disease caused by PStV. Quick recovery plants (score 1) were those that showed chlorotic ring mottle symptoms on 1-3 leaves and no symptoms on newly emerging leaves. Slow recovery (score 2) plants were those that showed chlorotic ring mottle symptoms on at least 4 leaves and no symptoms on newly emerging leaves. Less susceptible (score 3) plants were those that showed chlorotic ring mottle symptoms on one leaf and all newly emerging leaves. Susceptible plants (score 4) were those that showed severe blotch symptoms on one leaf and all newly emerging leaves (Figure 1).

Even though transgenicity of the parent plants G(8.10.8.1), G(8.10.8.2), G(8.10.8.4), G(8.10.8.5), $\mathrm{G}(9.2 .5 .2)$, and $\mathrm{G}(9.2 .5 .5)$ used in the hybridization were not directly confirmed using Southern analysis, they were in fact transgenic using the following explanation. As indicated (Figure 2), the plant lines $\mathrm{G}(8.10 .8 .6 .3), \mathrm{G}(9.2 .5 .1 .1)$ and $\mathrm{G}(9.2 .5 .1 .2)$ have been proven to be transgenic, each showing only one band. Because G(8.10.8.6.3) was derived from selfing of $\mathrm{G}(8.10 .8 .6), \mathrm{G}(8.10 .8 .6)$ was also transgenic, and in fact, this plant showed resistance to PStV. Because
$\mathrm{G}(8.10 .8 .6)$ was resulted from selfing of $\mathrm{G}(8.10 .8)$, $\mathrm{G}(8.10 .8)$ was also transgenic, and in fact this plant exhibited resistance to PStV. Because G(8.10.8) and $\mathrm{G}(8.10 .8 .6)$ were transgenic, the plant lines used in this experiment i.e. $G(8.10 .8 .1), \quad G(8.10 .8 .2)$, $\mathrm{G}(8.10 .8 .4)$, and $\mathrm{G}(8.10 .8 .5)$ were also transgenic. Using the same logic, other parent plants used in this experiment i.e. $G(9.2 .5 .2)$ and $G(9.2 .5 .5)$ were also transgenic because $\mathrm{G}(9.2 .5 .1 .1)$ and $\mathrm{G}(9.2 .5 .1 .2)$ were transgenic as shown by southern analysis.

All crosses between transgenic T4 plant lines and non-transgenic WS line resulted in F1 plants that all showed less susceptible response (score 3), except a cross between $G(9.2 .5 .3)$ and WS line that resulted in F1 plants consisting of those showing less susceptible (score 3) and susceptible response (score 4). These F1 plants were not analyzed further. F2 plants used in this experiment were those derived from crosses leading to F1 plants that showed less susceptible response (score 3)(Figure 3). The use of these F2 plants was to guarantee that their parents were homozygote in term of the transgene. In addition, the F2 plants analyzed were those derived from each F1 plant.

Based on Southern analysis and what previously put forward, the parent line $G(8.10 .8 .1), G(8.10 .8 .2)$, $\mathrm{G}(8.10 .8 .4)$, and $\mathrm{G}(8.10 .8 .5)$ probably carried only one copy transgene of $1.1 \mathrm{~kb}$ (Figure 2). Suppose the transgene is designated as $\mathrm{T}$, and no transgene is $\mathrm{t}$, then according the Mendel Law, the F2 population should consist of plants having genotypes TT, Tt, and tt following the ratio $1: 2: 1$. In other words, the F2 population should contain transgenic plants (TT and $\mathrm{Tt})$ and non-transgenic ones (tt) following 3:1 ratio. Since the F2 population was not subjected to molecular analysis, their transgenicity was not directly known. Instead, their transgenicity was indirectly determined by their phenotypes, i.e. resistant plants (score 0) : less susceptible plants (score 3) : susceptible plants (score 4) should follow 1:2:1 ratio. However, results of the experiment showed that there were other phenotypes found in the F2 population, i.e. quick recovery (score 1 ) and slow recovery (score 2). Even though we did not know the genotypes of those particular plants, they must be transgenic, and according to the Mendel Law the F2 population should consist of transgenic plants and non-transgenic ones following 3:1 ratio. Table 2 showed that some 

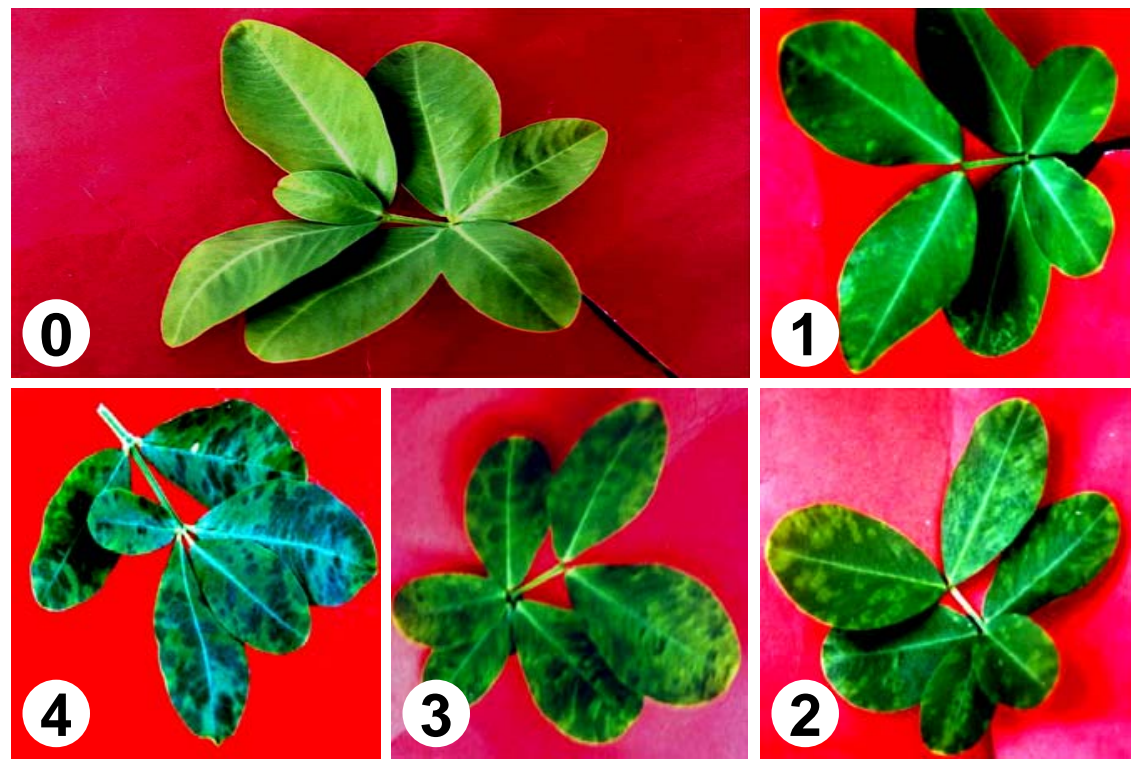

Figure 1. Symptoms of disease caused by PStV indicated by scores (number in each picture). Score 0 = resistant; plant did not show disease symptom caused by PStV. Score 1 = quick recovery; plants showed chlorotic ring mottle symptoms on 1-3 leaves and no symptoms on newly emerging leaves. Score $2=$ slow recovery ; plants showed chlorotic ring mottle symptoms on at least 4 leaves and no symptoms on newly emerging leaves. Score $3=$ less susceptible, plants showed chlorotic ring mottle symptoms on a leaf and showed the same symptom on all newly emerging leaves. Score $4=$ susceptible; plants showed severe blotch symptoms on a leaf and showed the same symptom on all newly emerging leaves.

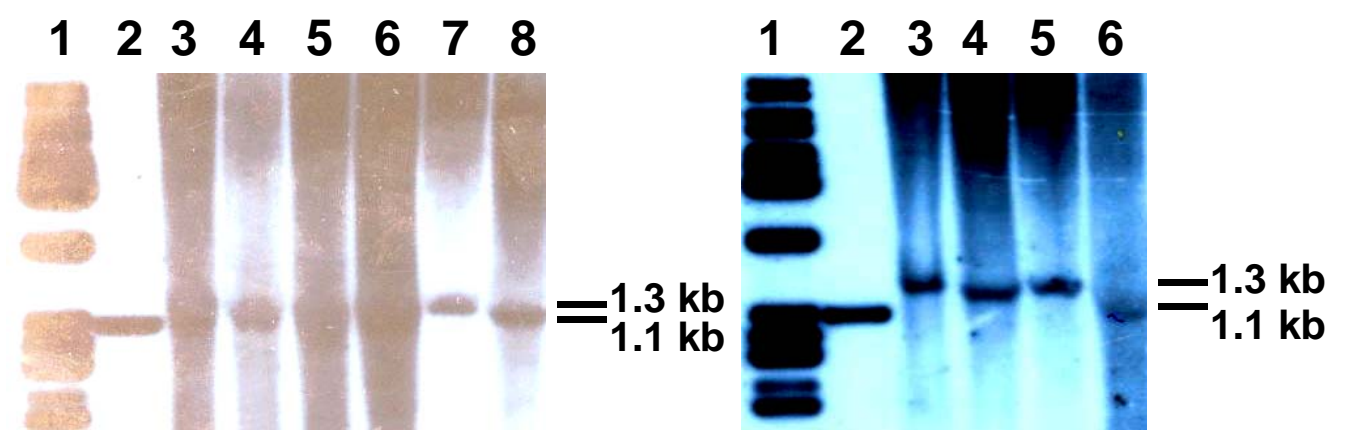

Figure 2. Southern analysis of some T5 transgenic peanut lines. Left: $1=1 \mathrm{~kb}$ ladder, $2=$ positive control, $3=$ $\mathrm{G}(8.15 .4 .1 .1), 4=\mathrm{G}(8.15 .4 .1 .2), 5=\mathrm{G}$ (8.17.1.1.1), $6=\mathrm{G}(8.17 .1 .1 .2), 7=\mathrm{G}(9.2 .5 .1 .1), 8=$ $\mathrm{G}(9.2 .5 .1 .2)$. Right: $1=1 \mathrm{~kb}$ ladder, $2=$ positive control, $3=\mathrm{G}(18.1 .5 .1 .3), 4=\mathrm{G}$ (8.15.4.1.3), $5=$ $\mathrm{G}(8.14 .4 .1 .2), 6=\mathrm{G}(8.10 .8 .6 .3)$ 


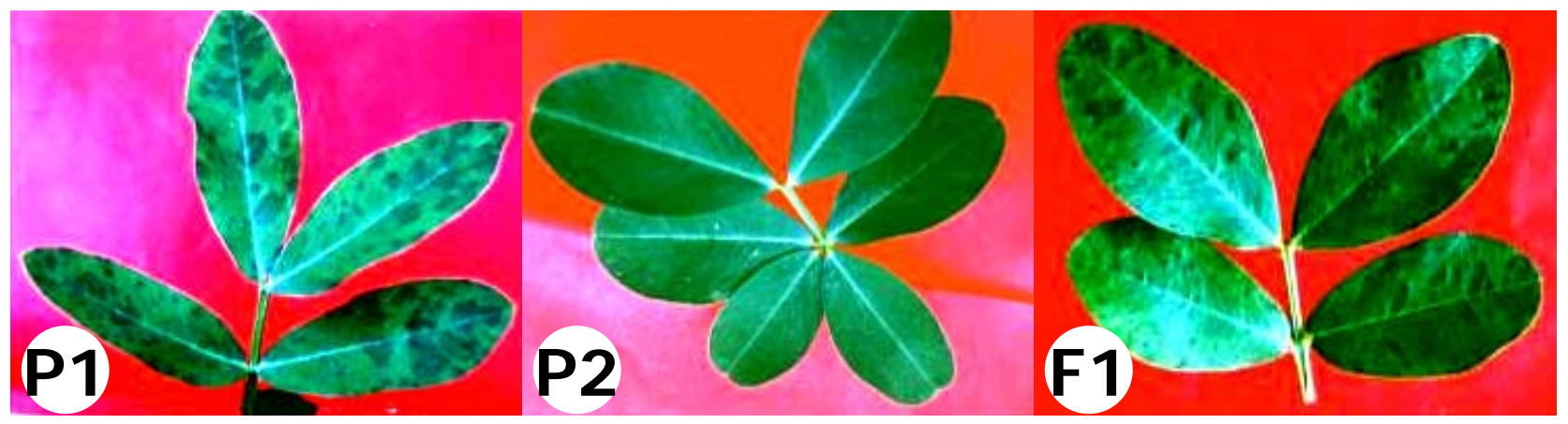

Figure 3. Response of non-transgenic peanut plants WS (P1), transgenic peanut plants cv.Gajah (P2), and F1 plants to PStV inoculation. F1 plants were resulted from crosses between P1 and P2.

crosses resulted in F2 population with the proportion of transgenic plants (score $0,1,2$, and 3 ) and nontransgenic plants (score 4) following 3:1 ratio while others did not follow the ratio.

As previously reported, peanut lines containing transgene $1.1 \mathrm{~kb}$ and $1.3 \mathrm{~kb}$ showed resistance or recovery phenotypes after they were mechanically inoculated with PStV (Hapsoro et al., 2007a). It was deductively stated that the two transgene were located at different loci, even at different chromosomes so that they could get separated during meiosis (Hapsoro et al., 2007a). Based on the Southern analysis of some $\mathrm{T} 5$ plants, it could be inferred that $\mathrm{T} 4$ parent plants used in this experiment contain either transgene $1.1 \mathrm{~kb}$ and $1.3 \mathrm{~kb}$, or both.

If transgenic parent T4 plants are homozygote, a cross with non-transgenic parent will lead to F1 population consisting of the same heterozygote plants and accordingly the same phenotypes. As an illustration, if the transgenic parent plants were designated as TT and non-transgenic parent plants tt, all F1 plants will have Tt genotypes, which according to this experiment resulted in less susceptible phenotypes. Table 1 showed that a cross between transgenic T4 parent plants G(9.2.5.3) and nontransgenic parent WS produced F1 plants consisting of less susceptible and susceptible plants, indicating heterozygousity of G (9.2.5.3). Therefore, only F2 population derived from one less susceptible F1 plant was analyzed.

The F1 plants that were less susceptible suggested that the transgene was partially dominant or incomplete dominant. Characters of resistance appeared when they were in homozygote condition.
This data was consistent with phenotypic data of T0 plant (primary transformant) that showed less susceptible to PStV (Hapsoro et al., 2005). The T0 plant was most likely heterozygote (hemizygote) for the transgenes integrated in the genomes because the probability of getting homozygote transgenes in plant genetic engineering was slim. Through several generations of selfing, this T0 plant produced progenies, some of which being resistant (Hapsoro et al., 2007b). This suggested that transgene homozygousity due to selfing caused the appearance of resistance character.

Table 2 showed that some individual F1 plants produced F2 progenies that were segregated following the Mendel Law, i.e. the proportion of transgenic plants (score 0, 1, 2, and 3) and non-transgenic plants (score 4) followed 3:1 ratio. The appearance of quick (score 1) and slow recovery (score 2) was not expected. What was expected was that F2 population only consisted of resistant (score 0 ), less susceptible (score 3), and susceptible (score 4) plants, following 1:2:1 ratio.

A recovery phenotype exhibited by transgenic tobacco plants carrying Tobacco Etch Virus (TEV) $c p$ gene has been reported by Goodwin et al. (1996). Transgenic tobacco plants containing three or more copies of transgene showed resistance to TEV while those containing 1-2 copies exhibited recovery response to TEV inoculation. Tanzer et al (1997), who used plant genetic materials from Goodwin et al. (1996), reported the appearance of quick and slow recovery response. The more copies of transgene the transgenic plants had the quicker their recovery response to TEV inoculation. This is known as a gene 
Table 1. Response of F1 peanut plants to Peanut Stripe Virus (PStV) inoculation as indicated by scores

\begin{tabular}{|c|c|c|c|c|c|c|c|}
\hline \multirow{3}{*}{ No. } & \multirow{3}{*}{$\begin{array}{l}\text { Crosses between Non- } \\
\text { Transgenic WS and } \\
\text { transgenic T4 plants }\end{array}$} & \multirow{3}{*}{$\begin{array}{l}\text { Total Number } \\
\text { of F1 Plants }{ }^{1} \text { ) }\end{array}$} & \multicolumn{5}{|c|}{$\begin{array}{c}\text { Number of F1 Plants Showing Indicated } \\
\text { Scores }\end{array}$} \\
\hline & & & & & 01 & & \\
\hline & & & 0 & 1 & 2 & 3 & 4 \\
\hline 1 & WS/G(8.10.8.1) & 7 & 0 & 0 & 0 & 7 & 0 \\
\hline 2 & WS/G(8.10.8.2) & 3 & 0 & 0 & 0 & 3 & 0 \\
\hline 3 & WS/G(8.10.8.3) & 4 & 0 & 0 & 0 & 4 & 0 \\
\hline 4 & WS/G(8.10.8.4) & 1 & 0 & 0 & 0 & 1 & 0 \\
\hline 5 & WS/G(8.10.8.5) & 8 & 0 & 0 & 0 & 8 & 0 \\
\hline 6 & WS/G(9.2.5.1) & 1 & 0 & 0 & 0 & 1 & 0 \\
\hline 7 & WS/G(9.2.5.2) & 1 & 0 & 0 & 0 & 1 & 0 \\
\hline 8 & WS/G(9.2.5.3) & 6 & 0 & 0 & 0 & 4 & 2 \\
\hline 9 & WS/G(9.2.5.5) & 1 & 0 & 0 & 0 & 1 & 0 \\
\hline
\end{tabular}

${ }^{1}$ ) F1 plants were resulted from crosses between transgenic T4 peanut plants cv. Gajah carrying PStV $c p$ gene and non-transgenic peanut plants WS. The transgenic T4 plants were resistant to PStV, while the nontransgenic plants WS were susceptible to PStV.

$\left.{ }^{2}\right)$ As described in Figure 1.

Table 2. Segregation of F2 population resulted from crosses between non-transgenic peanut plants WS and transgenic peanut plants cv. Gajah carrying PStV $c p$ gene. The non-transgenic parents were susceptible to PStV, while the transgenic ones were resistant to PStV

\begin{tabular}{lccccccc}
\hline & \multicolumn{9}{c}{ Number of F2 Plants $^{*}$ F1 Plants } & \multicolumn{4}{c}{ Score $^{\mathbf{1}}$} & $\begin{array}{c}\text { Ratio of Number of } \\
\text { Plants Showing Scores } \\
\text { (0+1+2+3) : score 4) }\end{array}$ & Remark $^{2}$ \\
\cline { 2 - 9 } & $\mathbf{0}$ & $\mathbf{1}$ & $\mathbf{2}$ & $\mathbf{3}$ & $\mathbf{4}$ & \\
\hline WS/G9CP3 (8.10.8.1).5 & 3 & 2 & 1 & 0 & 1 & $6: 1$ & $\mathrm{NM}$ \\
WS/G9CP3 (8.10.8.2).1 & 10 & 3 & 1 & 7 & 8 & $21: 8$ & $\mathrm{M}$ \\
WS/G9CP3 (8.10.8.2).2 & 14 & 0 & 2 & 9 & 9 & $25: 9$ & $\mathrm{M}$ \\
WS/G9CP3 (8.10.8.2).7 & 6 & 0 & 0 & 2 & 3 & $8: 3$ & $\mathrm{NM}$ \\
WS/G9CP3 (8.10.8.4).1 & 4 & 0 & 3 & 1 & 1 & $8: 1$ & $\mathrm{M}$ \\
WS/G9CP3 (8.10.8.5).1 & 3 & 0 & 2 & 3 & 3 & $8: 3$ & $\mathrm{NM}$ \\
WS/G9CP3 (8.10.8.5).4 & 2 & 0 & 1 & 1 & 3 & $4: 3$ & $\mathrm{M}$ \\
WS/G9CP3 (9.2.5.2).2 & 7 & 0 & 1 & 1 & 16 & $9: 16$ & \\
WS/G9CP3 (9.2.5.5).1 & 15 & 1 & 1 & 14 & 10 & $31: 10$ &
\end{tabular}

${ }^{1}$ As described in Figure 1.

${ }^{2} \mathrm{M}=$ Mendelian; $\mathrm{NM}$ = Non-Mendelian

dosage phenomenon (Goodwin et al., 1996; Tanzer et al., 1997).

In this experiment, the phenomenon of gene dosage did not seem to occur. The less susceptible phenotype of $\mathrm{F} 1$ was probably due to allelic interaction and not due to less copy number of the transgene. Likewise, the quick and slow recovery phenotype of some F2 plants might not be due to less copy number of the transgenes. Even though F2 population was not subjected to Southern analysis, the 
quick and slow recovery plants must be transgenic and they might have genotype TT or Tt. Teble 2 showed that among F2 population that was segregated following the Mendel Law, the proportion of resistant plants was higher than expected and the proportion of less susceptible plants was smaller than expected. The expected ratio of F2 population was 1:2:1 for resistant : less susceptible : susceptible (TT:Tt:tt $=1: 2: 1)$. This suggested that some of the Tt plants had quick and slow recovery phenotypes and resistant phenotypes.

It was also possible that some of TT plants showed recovery phenotypes as reported by other researchers. This occured because post transcriptional gene silencing mechanism could undergo meiotic resetting (Tanzer et al., 1997; Depicker and Montagu, 1997; Stam et al., 1997; Matzke and Matzke, 1998). In this case, resistance mechanism need to restart at every generation. As a result, at early stage of growth, transgenic plants are still susceptible to the virus in question and later become resistant after the resistance mechanism works. Therefore, it is recommended that breeding programs involving transgenic characters of resistance to virus should employ virus inoculation at later stage of plant growth to make sure that the resistance mechanism has worked (Butterfield et al., 2002).

In this experiment, meiotic resetting might not occur in F2 population because if it did occur, more TT plants would have had recovery phenotypes. Therefore, F2 population would have shown the proportion of resistant plants that was smaller than expected according to the Mendel Law.

\section{CONCLUSION}

PStV $c p$ transgene has been proved to be functional in peanut plants resulted from crosses between transgenic peanut parents coferring PStV $c p$ gene and non-transgenic ones. Resistance to PStV was partially dominant because the F1 plants showed less susceptible phenotypes. Even though phenotipic proportion in the F2 population was not mendelian, the proportion of transgenic and non-transgenic plants in the F2 population was mendelian.

\section{ACKNOWLEDGEMENT}

Many thanks were extended to the Directorate General of Higher Education, the Department of
National Education of Indonesia for funding this research and Queensland Agricultural Biotechnology Centre, Australia, for providing facilities to do Southern analysis.

\section{LITERATURES CITED}

Akin H.M., R. Suseno, \& Sudarsono. 1999. Variasi biologi dan molekuler strain-strain PStV (peanut stripe potyvirus) yang diisolasi dari berbagai pertanaman kacang tanah di Indonesia. Buletin Hama dan Penyakit Tumbuhan 11: 5661.

Avivi S. 2000. Berbagai Tipe Konstruksi Gen $c p$ PStV yang Dapat Memproteksi Tanaman Nicotiana benthamiana Transgenik terhadap Infeksi PStV pada Kacang Tanah. Disertasi. Program Pascasarjana Institut Pertanian Bogor.

Butterfield, M.K., J.E. Irvine, M.V. Garza, \& T.E. Mirkov. 2002. Inheritance and segregation of virus and herbicide resistance transgenes in sugarcane. Theor. App.l Genet. 104: 797-803.

Depicker A \& van M. Montagu. 1997. Posttranscriptional gene silencing in plants. Curr.Opin. Cell. Biol. 9: 373-382.

Goodwin, J., K.Chapman, S. Swaney, T. Dawn, T.D. Parks, E.A. Wernsman, \& W.G. Dougherty. 1996. Genetic and biochemical dissection of transgenic RNA-mediated virus resistance. The Plant Cell 8: 95-105.

Hapsoro, D., H. Aswidinnoor, R. Suseno, Jumanto, \& Sudarsono. 2005. Transformasi tanaman kacang tanah (Arachis hypogaea L.) dengan gen cp PStV dengan bantuan Agrobacterium. Jurnal Agrotropika 10: 85-93.

Hapsoro, D., H. Aswidinnoor, R. Suseno, Jumanto, \& Sudarsono. 2007a. Transgene identity and number of integration sites and their correlation with resistance to PStV in transgenic peanuts carrying Peanut Stripe Virus (PStV) coat protein gene. Jurnal Hama dan Penyakit Tumbuhan Tropika 7: 39-47. 
Hapsoro, D., H. Aswidinnoor, R. Suseno, Jumanto, \& Sudarsono. 2007b. Resistance to Peanut Stripe Virus (PStV) in transgenic peanuts (Arachis hypogaea L.) carrying PStV $c p$ gene was stabile up to seven generations of selfing. Biota 12: 8391.

Matzke, A.J.M. \& M.A. Matzke. 1998. Position effects and epigenetic silencing of plant transgenes. Curr.Opin.Plant Biol.1: 142-148.

Peach, C. \& J. Velten. 1991. Transgene expression variability (position effects) of CAT and GUS reporter genes driven by linked divergent $\mathrm{T}$ DNA promoters. Plant Mol Biol 17: 49-60.

Spencer, T.M., J.V. O’Brien, W.G. Start, T.R. Adams, W.J. Gordon-Kamm, \& P.G. Lemaux. 1992. Segregation of transgenes in maize. Plant Mol Biol 18: 201-210.
Stam, M., J. Mol, \& J. Kooter. 1997. The silence of genes in transgenic plants. Ann. Bot. 79:3-12.

Walters, D.A., C.S. Vetsch, D.E. Potts, \& R.C. Lundquist. 1992. Transformation and inheritance of a hygromycin phosphotransferase gene in maize plants. Plant Mol Biol 18: 189200.

Yasin, N. 2001. Evaluasi ketahanan tanaman transgenik model Nicotiana benthamiana terhadap peanut stripe virus. Tesis. Program Pascasarjana Institut Pertanian Bogor. 61 hal. 